\title{
CORPOS (IN)DÓCEIS: A CIRURGIA BARIÁTRICA EM SEU EFEITO DISCIPLINAR E BIOPOLÍTICO
}

\author{
BODY (IN)DOCILE: BARIATRIC SURGERY IN ITS DISCIPLINARY AND BIOPOLITICAL EFFECT \\ CUERPOS (IN)DÓCILES: LA CIRUGÍA BARIÁTRICA EN SU EFECTO DISCIPLINARIO Y \\ BIOPOLÍTICO
}

\section{Larissa Baldoíno da Paixão* \\ Márcia Stengel*}

\begin{abstract}
RESUMO
Na cena contemporânea, a aparência do corpo tem centralidade única. É nesse contexto que a obesidade foi considerada pela Organização Mundial de Saúde como uma epidemia mundial. A cirurgia bariátrica e metabólica vem se popularizando nas últimas décadas como opção de tratamento a essa condição. Este trabalho tem por objetivo articular a obesidade como categoria médico-clínica e sua relação com as formas de poder. Em seu efeito disciplinar, a técnica intervém sobre o corpo individual tornando-o mais “dócil”. Em seu efeito biopolítico, define as condições sobre a vida com base em termos quantitativos e universais. A epidemia da obesidade reflete os efeitos de um modelo socioeconômico que impregnou todas as esferas da vida humana e no qual nada se pode recusar.
\end{abstract}

Palavras-chave: Obesidade. Cirurgia bariátrica. Poder disciplinar. Biopolítica.

\begin{abstract}
Body appearance has a unique central role in the contemporary scenario. It is in this context that obesity was considered by the World Health Organization as a worldwide epidemic. Bariatric and Metabolic Surgery has become popular in recent decades as an option for the treatment this condition. This study aims to interweave obesity as a medical-clinical category and its relationship with forms of power. In its disciplinary effect, the technique intervenes over the individual body making it more "docile". In its biopolitical effect, it defines conditions upon life based on quantitative and universal terms. The obesity epidemic reflects the effects of a socio-
\end{abstract}

Texto recebido em 19 de maio de 2017 e aprovado para publicação em 6 de março de 2018.

Apoio financeiro da Fapemig (Fundação de Amparo à Pesquisa do Estado de Minas Gerais).

‘Doutoranda em Psicologia pela Pontifícia Universidade Católica de Minas Gerais (PUC Minas), psicóloga. E-mail: larisbp@ gmail.com.

"Professora doutora no Programa de Pós-Graduação em Psicologia da PUC Minas. Endereço: Avenida Itaú, 525, $2^{\circ}$ subsolo Dom Cabral, Belo Horizonte-MG, Brasil. CEP: 30535-012. Telefone: (31) 3319-4568. E-mail: marciastengel@gmail.com. 
economic model that has pervaded all spheres of human life and in which nothing can be refused.

Keywords: Obesity. Bariatric surgery. Disciplinary power. Biopolitics.

\section{RESUMEN}

En la escena contemporánea, la apariencia del cuerpo tiene una centralidad única. Es en este contexto que la Organización Mundial de la Salud consideró la obesidad como una epidemia mundial. La cirugía bariátrica y metabólica se ha vuelto popular en las últimas décadas como una opción de tratamiento para esta afección. Este trabajo tiene como objetivo articular la obesidad como una categoría médico-clínica y su relación con las formas de poder. En su efecto disciplinario, la técnica interviene en el cuerpo individual haciéndolo más "dócil". En su efecto biopolítico, define las condiciones de la vida desde términos cuantitativos y universales. La epidemia de la obesidad refleja los efectos de un modelo socioeconómico que ha impregnado todas las áreas de la vida humana y en el cual nada se puede rechazar.

Palabras clave: Obesidad. Cirugía bariátrica. Poder disciplinar. Biopolítica.

\section{INTRODUÇÃO}

“Estou em meu corpo e não posso deixá-lo" (Corbain, 2012, p. 8).

$\Lambda \begin{aligned} & \text { OMS (Organización Mundial de la Salud, 2020) considera a obesidade } \\ & \text { como um problema prioritário nas políticas públicas devido a seus índices } \\ & \text { de morbimortalidade e custos para o sistema de saúde pública. A essa }\end{aligned}$ condição se associam diversas complicações clínicas, destacando-se diabetes, doenças cardiovasculares, hipertensão arterial, problemas articulares, dificuldades respiratórias, apneia do sono, entre outras (Wannmacher, 2016). Trata-se de uma condição complexa de etiologia multifatorial, que tem influências genéticas, psicológicas, sociais, culturais e metabólicas, sendo difícil definir sua causalidade. Curiosamente, é nesse contexto de culto ao corpo que a obesidade se destaca como epidemia do século XXI. A obesidade em caráter epidêmico indica os efeitos tardios de um modelo político-econômico que explora ao máximo a noção de liberdade e do livre consumo.

Nas últimas décadas, a cirurgia bariátrica e metabólica se popularizou como uma opção eficaz de tratamento para a redução do peso e melhoria das comorbidades associadas à obesidade (Venâncio, Conceição, \& Machado, 2011). O Brasil é o segundo país no mundo que mais realiza operações desse tipo, com 80 mil registros por ano, e fica atrás apenas dos Estados Unidos Essa intervenção 
se apresenta, para muitas pessoas, como sendo a possibilidade de transformar um corpo com o qual se tornou impossível conviver.

Como dispositivo cirúrgico criado por um saber da biomedicina, propõe um tratamento para a obesidade a partir de uma intervenção no trato gastrointestinal, por diferentes tipos de técnicas.

Neste artigo, propomos a compreensão desse procedimento em sua dupla dimensão: como uma técnica de neodocilização, que promete aumentar o rendimento do corpo em seus níveis de trabalho e de consumo; como efeito da biopolítica orientada por um discurso universalizante que trata da quantificação da vida humana. Contudo, como nos ensina Foucault (2006), não existe um poder absoluto. Haverá especificidades nos níveis de captura a esses dispositivos como também haverá sempre a possibilidade de retomada de si para o exercício de uma consciência mais reflexiva capaz de recuar ante as incessantes ofertas do mundo neoliberal.

\section{PERCURSO METODOLÓGICO}

Este artigo parte de uma tese doutorado em andamento que tem como eixo a experiência da cirurgia bariátrica e metabólica. Trata-se de uma pesquisa de abordagem qualitativa, de caráter exploratório, com fundamentação teórica orientada pelos trabalhos de Michel Foucault acerca da sociedade disciplinar e da biopolítica. Como parte do percurso metodológico, foi realizada uma pesquisa de campo, por meio de entrevistas semiestruturadas com 11 mulheres que fizeram a cirurgia bariátrica e metabólica havia, no mínimo, dois anos. As colaboradoras tinham idades entre 23 e 57 anos.

A pesquisa foi aprovada pelo Comitê de Ética em Pesquisa (CAAE 83547218.2.0000.5137). Todas as participantes assinaram o termo de consentimento livre e esclarecido.

Para este trabalho, serão utilizados alguns fragmentos das entrevistas, com a finalidade de ilustrar o tema em questão. A seguir, será abordada a discussão do poder disciplinar com base na escrita de Foucault (2018) em Vigiar e Punir: o nascimento das prisóes e sua vinculação com a experiência do corpo na Contemporaneidade. 


\section{OS CORPOS DÓCEIS}

Deleuze (1992) nos lembra que foi no século XX que a sociedade disciplinar atingiu seu apogeu. Tratava-se da etapa posterior ao modelo soberano que exercia o poder de fazer morrer e de como morrer, exibindo aos súditos o corpo supliciado dos condenados. Em 1757, na entrada principal da Igreja de Paris, iniciou-se o suplício de Damiens, o condenado por parricídio que protagonizou as primeiras páginas de Vigiar e Punir: o nascimento das prisóes (Foucault, 2018). Seu corpo foi submetido a um ritual de execução em praça pública. Os gritos de Damiens ecoaram pela França do século XVIII, atestando o poder ilimitado do rei sobre os súditos: poder de fazer morrer e deixar viver.

Entre os séculos XVIII e XIX, ocorreu a progressiva suspensão dos suplícios (Foucault, 2018). A punição tornou-se menos explícita, buscando atingir menos a carne e mais os gestos, as condutas e a moral. Essa modalidade de poder se organizou a partir do investimento sobre os corpos individuais, com a finalidade de extrair sua força produtiva. O soldado exemplifica a possibilidade de modular o gesto e o corpo, a fim de aumentar sua eficácia. É o que Foucault (2018) define como "sociedade disciplinar". Tratava-se de uma organização social na qual se explorava "a mobilização das forças físicas do indivíduo", a fim de potencializar a força de produção (Negri, 2016, p. 71).

Os corpos eram distribuídos estrategicamente no espaço, seguindo estruturas rigorosamente hierárquicas: vide a disposição da sala de aula, o exército, a fábrica, o tribunal, o hospital, a igreja e as prisóes. Investiu-se na vigilância detalhada sobre os corpos mediante recursos como o registro escrito, a cronometragem do tempo, a localização no espaço. Os modos de coerção se aplicavam pela necessidade de cumprir as normas, compelindo à obediência. Tratava-se de "fazer crescer ao mesmo tempo a docilidade e a utilidade de todos os elementos do sistema" (Foucault, 2018, p. 211).

As grandes instituições caracterizaram esse tipo de organização social. Contudo o cenário após a Segunda Guerra Mundial precipitou uma crise progressiva dessas instituições de confinamento. Os modos de controle, portanto, também foram atravessados por essa transformação. Para Deleuze (1992), esse momento histórico não se adequava mais ao modelo disciplinar, mas sim à "sociedade de controle". Nesse modo de organização política e social, a coerção disciplinar ultrapassava as estruturas de confinamento. As paredes das fábricas cederam lugar à lógica empresarial, assim como no regime hospitalar delineou-se uma medicina "sem médico nem doente", dedicada a resgatar os "doentes potenciais e sujeitos a risco" (Deleuze, 1992, p. 4). 
Com efeito, as práticas disciplinares ultrapassaram o espaço físico das grandes instituições. Essa modalidade de poder não desapareceu. Ela se intensificou em novos espaços de confinamento sem grades: o espaço virtual, o espaço psíquico, os exames de imagem, as próteses farmacológicas: "O corpo já não habita os espaços disciplinadores: está habitado por eles.” (Preciado, 2018, p. 86). Esses espaços consolidam novos regimes de visibilidade nos quais a aparência do corpo adquire centralidade única.

Esse modelo compõe a formação de uma subjetividade na qual o controle foi internalizado. É o espaço do próprio corpo que se apresenta como objeto de uma vigilância incessante.

Em Microfisica do poder, Foucault (2013, p. 82) destaca a relação entre corpo e poder: "O domínio, a consciência de seu próprio corpo só puderam ser adquiridos pelo efeito do investimento do corpo pelo poder: a ginástica, os exercícios, o desenvolvimento muscular, a nudez, a exaltação do belo corpo". O investimento do poder sobre a materialidade do corpo se evidencia também nas produções discursivas acerca do corpo sadio.

A reprodução do Pan-óptico de Bentham é apresentada por Foucault (2018) em Vigiar e Punir: o nascimento das prisões. Essa estrutura arquitetônica apresenta um modelo de vigilância ideal: na perspectiva de uma torre central, seria possível observar todo o espaço ao redor. Um jogo de luz e sombra tornaria imperceptível a localização do vigia bem como o momento da inspeção. A invisibilidade do controle se faz presente no modelo de sociedade atual.

$\mathrm{Na}$ Contemporaneidade, o pan-óptico abandona sua literalidade, tornando-se imperceptível. O controle pela vigilância permanece como característica inerente ao universo da comunicação virtual (Han, 2018a). Tecnologias de rastreamento permitem identificar a localização de qualquer pessoa ou objeto. As informações sobre os consumidores são produtos altamente rentáveis para as empresas no mercado digital. Nesse novo formato disciplinar, diluem-se as fronteiras entre o que vigia e o que é vigiado. A submissão à vigilância é consentida, e o controle é interiorizado. Cabe, neste ponto, retomar o fragmento em que Foucault (2018, p. 126) destaca a sutileza do modelo disciplinar: "Pequenas astúcias dotadas de grande poder de difusão, arranjos sutis, de aparência inocente, mas profundamente suspeitos". Um tipo de controle aparentemente inofensivo, menos perceptível.

Uma vez bem instalado nas consciências individuais, o poder mantém a sua eficácia utilizando-se de ferramentas autoaplicáveis. É sobre o corpo que o olhar investe tanto em sua imagem estetizada quanto em sua dimensão biológica. $\mathrm{O}$ corpo reduzido a estatuto de objeto biológico se torna alvo de um tecnicismo que 
o investiga e o anatomiza visando ao detalhamento das partes. A fragmentação do organismo fomenta a produção de dados quantificáveis e saberes de uma medicina orientada para a hiperespecialização (Ortega, 2008).

O modelo disciplinar garantiu as condições necessárias para a gestão biopolítica. Para Foucault (2005), o poder disciplinar e o biopoder não se excluem, ao contrário, se sobrepõem e se complementam. O biopoder opera fora do campo das individualidades, investindo sobre a noção de população (com seu corpo de "inúmeras cabeças"). Esse dispositivo de controle se orienta para o que há de quantificável na vida da espécie humana: os dados estatísticos, as taxas de natalidade e mortalidade, as epidemias globais. Seus efeitos operam menos pelo detalhe, pela submissão à norma, e mais para uma regulamentação da vida como espécie. Enfim, o biopoder "substitui o corpo individual ou numérico pela cifra de uma matéria 'dividual' a ser controlada" (Deleuze, 1992, p. 4, grifo do autor). Caberia, dessa forma, ao Estado regulamentar cuidadosamente os modos de fazer viver de maneira a evitar "a subtração de forças, a diminuição do tempo de trabalho, baixa de energia, custos econômicos" (Foucault, 2005, p. 290).

Compreendemos que os espaços de confinamento permaneceram, mas não se organizam de modo explicitamente coercitivo: "O poder está precisamente onde não é posto em evidência" (Han, 2018b, p. 25). Não haveria mais o sujeito da obediência, pois o modelo neoliberal se torna mais eficaz na exploração da liberdade. Os espaços de confinamento do século XXI se estruturam com base na livre escolha: os apartamentos, as academias de ginástica, os consultórios, os veículos, os shoppings, a empresa. Assim, tomamos o exemplo do termo descrito por Han (2018b, p. 19) como "pan-ópticos digitais", no qual a vigilância é absolutamente descentralizada e compartilhada de modo consentido. Considera-se esse modelo como prática de neodocilização que perpetua regimes de visibilidade a fim de promover a manutenção da força produtiva. No regime neoliberal, a força produtiva equivale ao potencial de consumo.

\section{QUAL É O CORPO SAUDÁVEL?}

A noção do corpo sadio é amplamente vinculada à gestão biopolítica. Para Foucault (2005), os parâmetros que consolidam a categoria de "doença" não são ingenuamente construídos. Sobre o corpo da população, não basta:

Apenas descrevê-lo e quantificá-lo - por exemplo, em termos de nascimento e de mortes, de fecundidade, de morbidade, de longevidade, de migração, de criminalidade, etc.-, mas também jogar com tais descriçôes e quantidades combinando-as, comparando-as e, sempre que possível, prevendo seu futuro por meio do passado (Danner, 2010, p. 154). 
Neste ponto, propomos uma discussão acerca da obesidade como problema de saúde pública e sua articulação com as estratégias de biopoder e disciplinarização dos corpos. Para Moulin (2011), o século XX correspondeu à era da medicalização da vida. Dessa forma, a partir das Ciências Médicas, promulgaram-se uma série de regras de comportamentos subsidiados pela ideia de prevenção a doenças. Regras que modulam condutas individuais, modificando a autonomia dos sujeitos com sua saúde e com seu corpo.

As práticas da medicina preventiva e o resultado de estudos epidemiológicos ressaltam a preocupação com o sobrepeso, considerando que este seria uma condição prévia à obesidade. A referência à obesidade aparece na Classificação Internacional das Doenças pela primeira vez em 1948. Contudo, foi em 1995 que a Organização Mundial de Saúde reconhece a obesidade como uma epidemia do mundo ocidental moderno (Organización Mundial de la Salud, 2020).

Com base em estudos estatísticos, detectou-se uma articulação entre o excesso de peso corporal e a diminuição da expectativa de vida. Desde então, apoiaramse investigações no intuito de identificar possíveis correlações entre determinadas patologias e a obesidade, destacando como resultado dessas pesquisas as doenças cardiovasculares e diabetes tipo 2 (Poulain, 2013).

As empresas de seguros de saúde nos Estados Unidos passaram a investir em estudos que relacionavam a obesidade à mortalidade precoce, além dos gastos com a saúde (Poulain, 2013). Uma série de instituições e organizações se dedicaram a investigar o tema da obesidade, considerando seu potencial de risco à saúde. Em 2016, a Organização Mundial de Saúde (World Health Organization, 2016) definiu a obesidade como um problema prioritário para as políticas públicas. Dois argumentos se destacaram nessa questão: um diz respeito aos altos índices de morbimortalidade da população obesa, e o outro é financeiro: a obesidade e as comorbidades associadas acarretam elevados custos para o sistema de saúde pública. No Brasil, dados alarmantes afirmam que mais de $50 \%$ da população adulta estariam acima do peso (Agência Nacional de Saúde Suplementar, 2017).

No campo médico-científico, há um consenso a respeito dos prejuízos causados pelo sobrepeso e pela obesidade, em seus efeitos clínicos e sociais. Não obstante, considera-se que a abordagem dessa complexa condição deve priorizar estratégias macropolíticas direcionadas para a redução do ambiente obesogênico. Neste ponto, ressaltamos os seguintes eixos: a melhoria das condições de trabalho, a segurança pública (o medo da violência conduz às praças de alimentação dos grandes centros comercias), o sistema de transporte, os modos de circulação nas cidades, o acesso a alimentos in natura e livres de agrotóxicos. No Brasil, ainda é permitido o uso de substâncias que já foram proibidas nos Estados Unidos 
e na União Europeia (Oliveira \& Moraes, 2019). De acordo com o Instituto Nacional do Câncer (2018), o contato e a exposição aos agrotóxicos podem ocasionar inúmeras doenças e afetam principalmente a saúde dos trabalhadores agrícolas, embora toda a população também esteja vulnerável à toxidade desses produtos. Essa pauta é tão importante quanto a discussão acerca da obesidade.

Essa informação evidencia a relatividade da gestão biopolítica que bem seleciona seus critérios de cuidado com a saúde da população. Como "fazer viver" e "deixar morrer" grupos específicos? Retomamos aqui o questionamento posto por Foucault (2006, p. 226): "A qual regra somos obrigados a obedecer, em uma certa época, quando se quer ter um discurso científico sobre a vida?".

No contexto neoliberal, o corpo somente pode ter sentido conforme reproduza práticas de consumo. Nesse sentido, é pertinente mencionar que miséria social e a escassez de alimentos ainda representam um problema mundial. A invisibilidade daqueles que são afetados pela escassez de recursos e pelas consequências da fome parece ser rompida somente pela frieza dos dados estatísticos. O problema da escassez alimentar e seu relativo silenciamento é abordado por Sibilia (2006, p. 105): "A conclusão é óbvia: apesar de serem muitos, quase tantos (ou mais) que os gordos e obesos, eles simplesmente não contam. Não constituem um mercado, não são consumidores". Destarte, outro tipo de narrativa é atribuído ao tema da obesidade, geralmente sob a égide do saber das Ciências Médicas. $\mathrm{O}$ destaque dado à gordura corporal tanto na mídia quanto no discurso médico científico conduz à formulação de Foucault (2005) a respeito da exploração política e econômica que subsumiu todas as esferas da vida humana.

O filósofo Han (2018b, p. 91), ao discutir o big data, caracteriza uma lógica empresarial que classifica pessoas em categorias, conforme seu potencial de consumo. Assim, as pessoas "com um valor econômico baixo são denominadas com o termo waste (lixo)". A invisibilidade da fome, condição que destrói vidas tanto quanto a obesidade, obedece à lógica da neodocilização dos corpos, estabelecendo critérios a favor de "determinadas vidas".

Butler (2018) nos ensina que a distribuição dos níveis de precariedade recai sobre a população de modo bastante desigual e obedece a regras bem estabelecidas. Nesse sentido, destaca-se aqui a construção da obesidade como categoria médicoclínica como um produto da gestão biopolítica. $\mathrm{O}$ corpo obeso revela na carne os efeitos de um modelo econômico orientado para o livre consumo, no qual nada se pode recusar.

Para Recalcati (2002), a dinâmica da obesidade em sua manifestação fenomenológica exemplifica a plena adesão ao discurso capitalista. Nesse circuito, os objetos perdem o sentido simbólico e se convertem em mercadorias 
sempre disponíveis. O discurso capitalista promete tanto a resolução das necessidades quanto a produção de pseudonecessidades, garantindo assim a eficácia do sistema. $\mathrm{O}$ objeto da necessidade, neste caso, o alimento, encontrase sempre disponível à devoração e à consumação. Nesse ponto, destaca-se a simultaneidade dos processos de subjetivação, em seus efeitos singulares, e a organização sociopolítica da vida coletiva.

Dessa forma, a obesidade cumpre a função de nada recusar, em um movimento incessante de consumo e acumulação. $\mathrm{O}$ corpo obeso evidencia, sem decoro, $\mathrm{o}$ nível de seus descomedimentos. A gordura corporal em excesso é vivida como um estorvo, uma sobra sem destinação. Nada disso difere do registro neoliberal, exceto a possibilidade de descarte das mercadorias acumuladas. Os objetos obsoletos podem ser facilmente descartados; a gordura corporal acumulada não[. . .] não com tanta facilidade.

\section{UMA PROPOSTA DE CURA}

Em resposta à emergência da obesidade como categoria clínica, uma técnica biomédica vem se popularizando nas últimas décadas como uma opção de tratamento a essa condição: a cirurgia bariátrica e metabólica. Trata-se de uma intervenção no trato gastrointestinal, por diferentes tipos de técnicas. Esse procedimento é considerado como uma opção eficaz de tratamento para a redução do peso e melhoria das comorbidades associadas à obesidade (Venâncio et al., 2011). Existem três procedimentos básicos: restritivos (que diminuem a quantidade de alimentos que o estômago é capaz de comportar), disabsortivos (que reduzem a capacidade de absorção do intestino) e técnicas mistas (com pequeno grau de restrição e desvio curto do intestino com discreta má absorção de alimentos). A cirurgia é indicada quando os tratamentos clínicos convencionais não obtiveram resultados satisfatórios há pelo menos dois anos. $\mathrm{O}$ Brasil é o segundo país no mundo que mais realiza operações desse tipo, sendo que $76 \%$ desse público são mulheres (Battistelli, 2018). A Sociedade Brasileira de Endocrinologia e Metabologia (2012) adverte sobre a complexidade desse procedimento, sendo passível a riscos e complicações posteriores. Alguns estudos apontam que, após dois anos de cirurgia, parece haver uma diminuição dos benefícios pós-cirúrgicos. Nisso se inclui o risco de reganho de peso (Venâncio et al., 2011), comportamento alimentar inadequado, tais como o "petisco contínuo" e ingestão alimentar compulsiva (Conceição et al., 2018). Embora haja um aumento contínuo no número de realizações de cirurgia bariátrica no Brasil, a orientação para o controle e tratamento da obesidade envolve estratégias 
de políticas intersetoriais e de segurança alimentar (Organização Pan-Americana da Saúde, 2017).

Consideramos que a cirurgia bariátrica e metabólica exemplifica a relação entre o poder disciplinar (atuando na esfera individual, no registro do corpo) e a biopolítica, na esfera populacional que bem seleciona e caracteriza seu lócus epidêmico, ainda que nem sempre se disponha a encontrar soluçôes a favor da vida. Consideremos aqui o argumento de Butler (2018), ao afirmar que a vida não é resumida a sua mera condição biológica de "ser vivo". Se a saúde é a favor da vida, ela teria como princípio fundamental tornar a vida possível em suas condições básicas de sobrevivência.

\section{CONSIDERAÇÕES FINAIS}

A cirurgia bariátrica e metabólica pode ser compreendida em sua dupla dimensão: por um lado, tem efeito disciplinar, tornando os corpos mais "dóceis", mais produtivos. Por outro, a transformação radical na aparência corporal, assim como as restrições alimentares impostas pela cirurgia podem favorecer a um reposicionamento subjetivo com maior possibilidade de recusa ao livre consumo. Propusemos, neste artigo, a abordagem da cirurgia bariátrica e metabólica como um dispositivo de controle disciplinar e biopolítico sobre os corpos.

A obesidade em caráter epidêmico revela os efeitos tardios de um modelo político-econômico que explora, de modo eficaz, a noção de liberdade e do livre consumo. Como estratégia biopolítica, vincula-se à massificação, à vida humana quantificada e representada em dados. A patologização da obesidade explora uma política do medo: medo de adoecer e de morrer, medo da exclusão e da recusa. Nesse circuito, extingue-se a potência das singularidades e do próprio corpo em assumir-se para além de sua pura biologia, para além de uma imagem estetizada.

O posicionamento aqui considerado é o de sustentar o corpo como um gesto ético-político, superfície viva que ultrapassa a condição biológica não somente pela dimensão ontológica do ser, como pelo simples fato de que o corpo biológico se tornou inverossímil. O que temos é um corpo cyber, fusão entre a prótese e o orgânico.

A experiência com o corpo deve suportar dissonâncias, divergências e resistências, permitindo espaço para a criação e também para o desconforto. É o corpo que reconhece sua vulnerabilidade sem, com isso, render-se a ela. Como bem nos ensina Foucault (2006, p. 232), todas as relaçôes de poder convocam, a cada instante, possibilidades de resistência: "Em toda parte, se está em luta". 
A condução macropolítica que favorece práticas de exclusão e de adestramento de corpos "dissonantes" convoca simultaneamente ações de resistência no âmbito das micropolíticas. O corpo, portanto, jamais abandona seu efeito político. Se a vida, em todas as suas dimensões, foi capturada por um poder que reduz a condição humana ao seu estado puramente biológico, a alternativa de sobrevivência está na retomada da ética do desejo. Trata-se de fazer perseverar, até as últimas consequências, a autenticidade do ser. 


\section{REFERÊNCIAS}

Agência Nacional de Saúde Suplementar (2017). Manual de diretrizes para o enfrentamento da obesidade na saúde suplementar brasileira. Rio de Janeiro: ANS. Recuperado a partir de https://www.ans.gov.br/images/Manual_de_ Diretrizes_para_o_Enfrentamento_da_Obesidade_na_Sa\%C3\%BAde_ Suplementar_Brasileira.pdf

Battistelli, C. (2018, 11 julho). Número de cirurgias bariátricas no Brasil aumenta 46,7\%. São Paulo: Sociedade Brasileira de Cirurgia Bariátrica e Metabólica. Recuperado a partir de https:/www.sbcbm.org.br/numero-de-cirurgiasbariatricas-no-brasil-aumenta-467/\#: - :text=Um\%20dos\%20reflexos\%20 do\%20crescimento,2017\%20aumentou $\% 2046 \% 2$ C7\%25.

Butler, J. (2018). Quadros de Guerra: Quando a vida é passivel de luto? Rio de Janeiro: Civilização Brasileira.

Conceição, E., Teixeira, F., Rodrigues, T., Lourdes, M., Bastos A., Pinto, A., . . . \& Ramalho, S. (2018). Comportamentos alimentares problemáticos após cirurgia bariátrica: um estudo com amostra nacional portuguesa. Revista Acta Médica Portuguesa, 31(11), 633-640. Recuperado a partir de https://doi. org/10.20344/amp.9237

Corbin, A. (2012). Introdução. In A. Corbin, J. J. Courtine, \& G. Vigarello, (Orgs.), História do corpo: da Revolução à Grande Guerra. (4a ed., Vol. 2, pp. 8-10). Petrópolis: Vozes.

Danner, F. (2010). O sentido da biopolítica em Michel Foucault. Revista Estudos Filosóficos, 4, 143-157.

Deleuze, G. (1992). Post-scriptum sobre as sociedades de controle. In Conversaçôes: 1972-1990. P. P. Pelbart (Trad.). (pp. 219-226). Rio de Janeiro: Ed. 34.

Foucault, M. (2005). Aula de 17 de março de 1976. In Em defesa da sociedade: curso no Collège de France (1975-1976). (pp. 285-315). São Paulo: Martins Fontes.

Foucault, M. (2006). Ética, estratégia, poder-saber. In M. B. Motta (Org.), Ditos e Escritos. (2a ed., vol. 4). Rio de Janeiro: Forense Universitária.

Foucault, M. (2013). Microfisica do poder. In R. Machado (Org.), A microfísica do poder (26a ed.). São Paulo: Graal. 
Foucault, M. (2018). Vigiar e punir: nascimento da prisão. (42a ed.). Petrópolis: Vozes.

Han, B.-C. (2018a). No enxame: perspectivas do digital. Petrópolis: Vozes.

Han, B.-C. (2018b). Psicopolitica: o neoliberalismo e as novas técnicas de poder. Belo Horizonte: Âyiné.

Instituto Nacional do Câncer. (2018). Agrotóxicos. Rio de Janeiro: INCA. Recuperado a partir de https://www.inca.gov.br/assuntos/agrotoxicos

Moulin, A. M. (2011). O corpo diante da medicina. In Corbin, A., Courtine, J.-J., \& Vigarello, G. (Org.), História do corpo: as mutaçôes do olhar: o século XX. (4a ed, vol. 3, pp. 15-82). Petrópolis: Vozes.

Negri, A. (2016). Quando e como eu li Foucault. São Paulo: N-1.

Oliveira, J. C., \& Moraes, G. (2019, 11 março). Deputados divergem sobre regra para registro de agrotóxicos. Agência Câmara Notícias, Brasília. Recuperado a partir de https://www.camara.leg.br/noticias/553157-deputados-divergemsobre-regra-para-registro-de-agrotoxicos/

Organização Pan-Americana da Saúde. (2017, 14 março). Em evento na OPAS/OMS Brasil assume metas para frear crescimento da obesidade até 2019. Brasília: OPAS. Recuperado a partir de https:/www.paho.org/ $\mathrm{bra} /$ index.php?option $=$ com_content $\& v i e w=$ article $\& i d=5366$ :em-eventona-opas-oms-brasil-assume-metas-para-frear-crescimento-da-obesidadeate-2019\&Itemid $=820 \#: \sim:$ text $=\mathrm{O} \% 20 \mathrm{Brasil} \% 20$ assumiu $\% 20 \mathrm{o} \% 20$ compromisso,adulta\%2C\%20at\%C3\%A9\%202019\%3B\%20e\%20ampliar

Organización Mundial de la Salud. (2020, $1^{\circ}$ abril). Obesidad y sobrepeso: datos y cifras. Genebra: OMS. Recuperado a partir de https://www.who.int/es/newsroom/fact-sheets/detail/obesity-and-overweight

Ortega, F. (2008). O corpo incerto: corporeidade, tecnologias médicas e cultura contemporânea. Rio de Janeiro: Garamond.

Porter, R., \& Vigarello, G. (2012). Corpo, saúde e doenças. In A. Corbin, J.-J. Courtine, \& G. Vigarello (Org.), História do corpo: da Renascença às Luzes. (5a ed., vol. 1, pp. 441-486). Petrópolis: Vozes.

Poulain, J.-P. (2013). Sociologia da obesidade. São Paulo: Editora Senac. 
Preciado, P. B. (2018). Texto junkie: sexo, drogas e biopolitica na era farmacopornográfica. São Paulo: N-1.

Recalcati, M. (2002). O "demasiado cheio" do corpo: por uma clínica psicanalítica da obesidade. Revista Latusa, 7, 51-74.

Sibilia, M. P. (2006). O pavor da carne: riscos da pureza e do sacrificio no corpoimagem contemporâneo. (Tese de Doutorado). Universidade do Estado do Rio de Janeiro, Instituto de Medicina Social. Rio de Janeiro. Recuperado a partir de https://edisciplinas.usp.br/pluginfile.php/3114954/mod_resource/ content $/ 2 /$ Tese $\% 20$ O $\% 20$ pavor\%20da $\% 20$ carne.\%20Paula $\% 20$ Sibilia $\% 20$ $\% 5 \mathrm{BUerj} \% 2 \mathrm{C} \% 202006 \% 5 \mathrm{D} . \mathrm{pdf}$

Sociedade Brasileira de Endocrinologia e Metabologia. (2012, 15 fevereiro). 10 coisas que você precisa saber sobre a cirurgia bariátrica. Rio de Janeiro: Sociedade Brasileira de Endocrinologia e Metabologia. Recuperado a partir de https:// www.endocrino.org.br/10-coisas-que-voce-precisa-saber-sobre-cirurgiabariatrical

Venâncio, C., Conceição, E., \& Machado, P. (2011). Avaliação dos padrões alimentares de pacientes bariátricos, na fase pós-operatória tardia. In A. M. Franques, \& M. S. Arenalis-Loli (Orgs.), Novos corpos, novas realidades: reflexōes sobre o pós-operatório da cirurgia da obesidade. (pp. 73-92). São Paulo: Vetor.

Wannmacher, L. (2016). Obesidade como fator de risco para morbidade e mortalidade: evidências sobre o manejo com medidas não medicamentosas. Uso racional de medicamentos: fundamentação em condutas terapêuticas e nos macroprocessos da assistência farmacêutica. Representação Brasil, 1(7). Recuperado a partir de https://www.paho.org/bra/index. php?option=com_docman\&view=download \&category_slug=serie-usoracional-medicamentos-284\&alias $=1535$-obesidade-como-fator-risco-paramorbidade-e-mortalidade-evidencias-sobre-o-manejo-com-medidas-naomedicamentosas $-5 \&$ Itemid $=965$

World Health Organization. (2016). Obesity and overweight. Geneve: WHO. Recuperado a partir de https://www.who.int/news-room/fact-sheets/detail/ obesity-and-overweight 